\title{
O LUGAR DE ROLAND BARTHES: ENTREVISTA COM ÂNGELA SENRA, ENEIDA MARIA DE SOUZA E VERA CASA NOVA
}

1. Fonte: Roland Barthes, Flammarion, 1990
Ângela Senra

Eneida Maria de Souza

Vera Casa Nova

Entrevista por: José Antônio

Entrevista po

\section{FRAGMENTOS DE UMA FOTOBIOGRAFIA ${ }^{1}$}

Os escritos e os ensinamentos de Roland Barthes (19151980) percorrem um dos caminhos mais originais da crítica e da teoria da cultura contemporâneas. Em sua trajetória biográfica e teórica, A câmara clara (La chambre claire, 1980), o último livro que publicou em vida, representa, de uma só vez, um momento de síntese e de ruptura - no que se refere às principais questões e conceitos desenvolvidos pelo autor em busca de uma teoria sobre a linguagem específica dos signos não-verbais.

Considerado por muitos como o mais autobiográfico de todos os livros que Barthes publicou - e, talvez, também o mais filosófico - A câmara clara apresenta um discurso fragmentado, francamente subjetivo e não linear, a meio-fio entre o ensaio e o romance. Relato afetivo, pontuado
* http://semioticas1.blogspot.com.br

José Antônio Orlando é jornalista, professor universitário, bacharel em Comunicação Social pela UFJF, mestre pela Faculdade de Letras da UFMG e autor do blog Semióticas.

de metalinguagem sobre a pesquisa e o método, mas longe de estabelecer uma metodologia reconfortante, esse livro, talvez mais do que todos os outros publicados, merece por certo o adjetivo "inquietante". As questões e conceitos elaborados por Barthes fundamentam esta seleção de imagens biográficas sobre sua trajetória. 


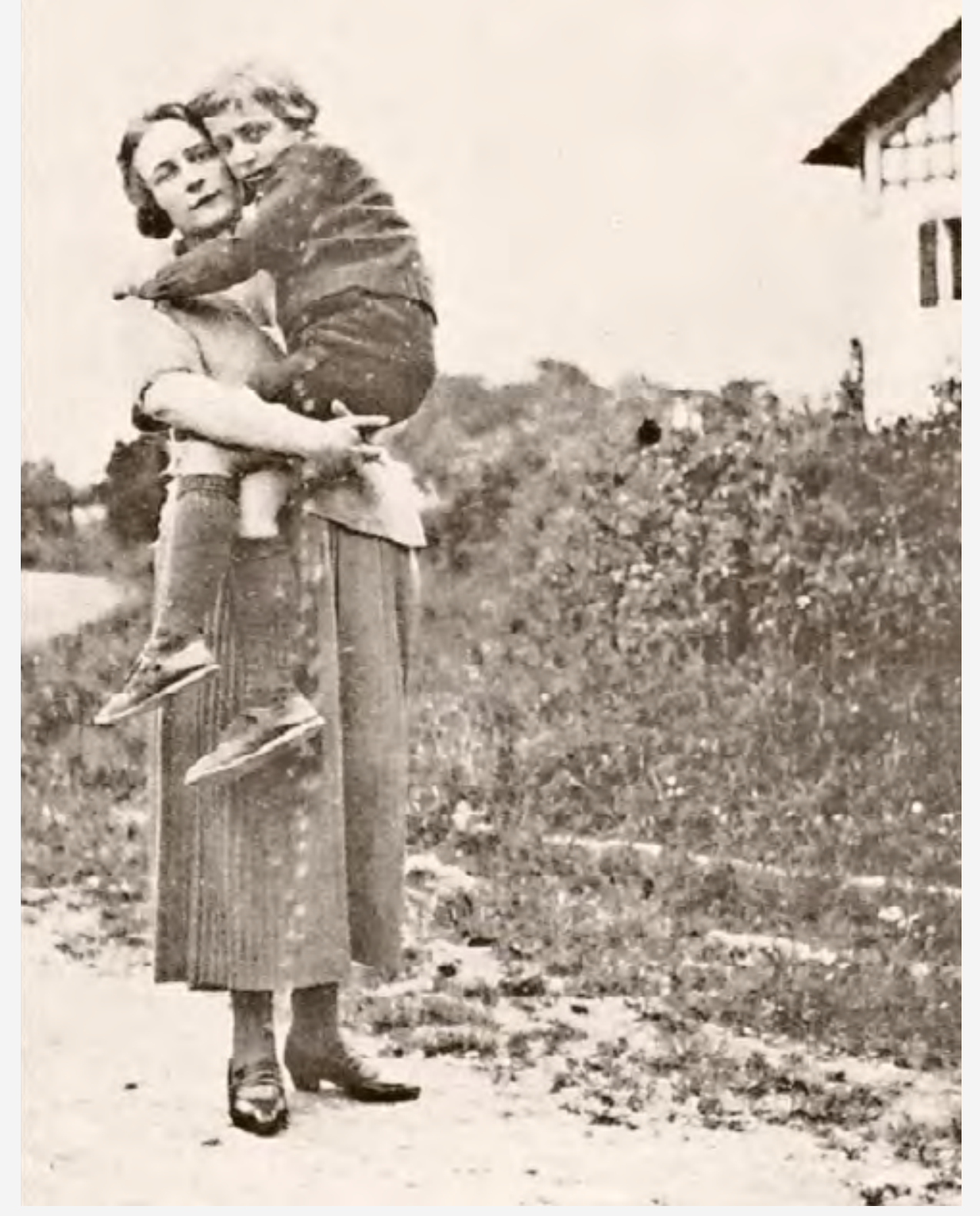

FIGURA 1

Roland Barthes aos 8 anos, em

1923, no colo de sua mãe, Henriette

Barthes, fotografados em frente

à casa da família em Cherbourg-

Octeville, região Norte da França. 


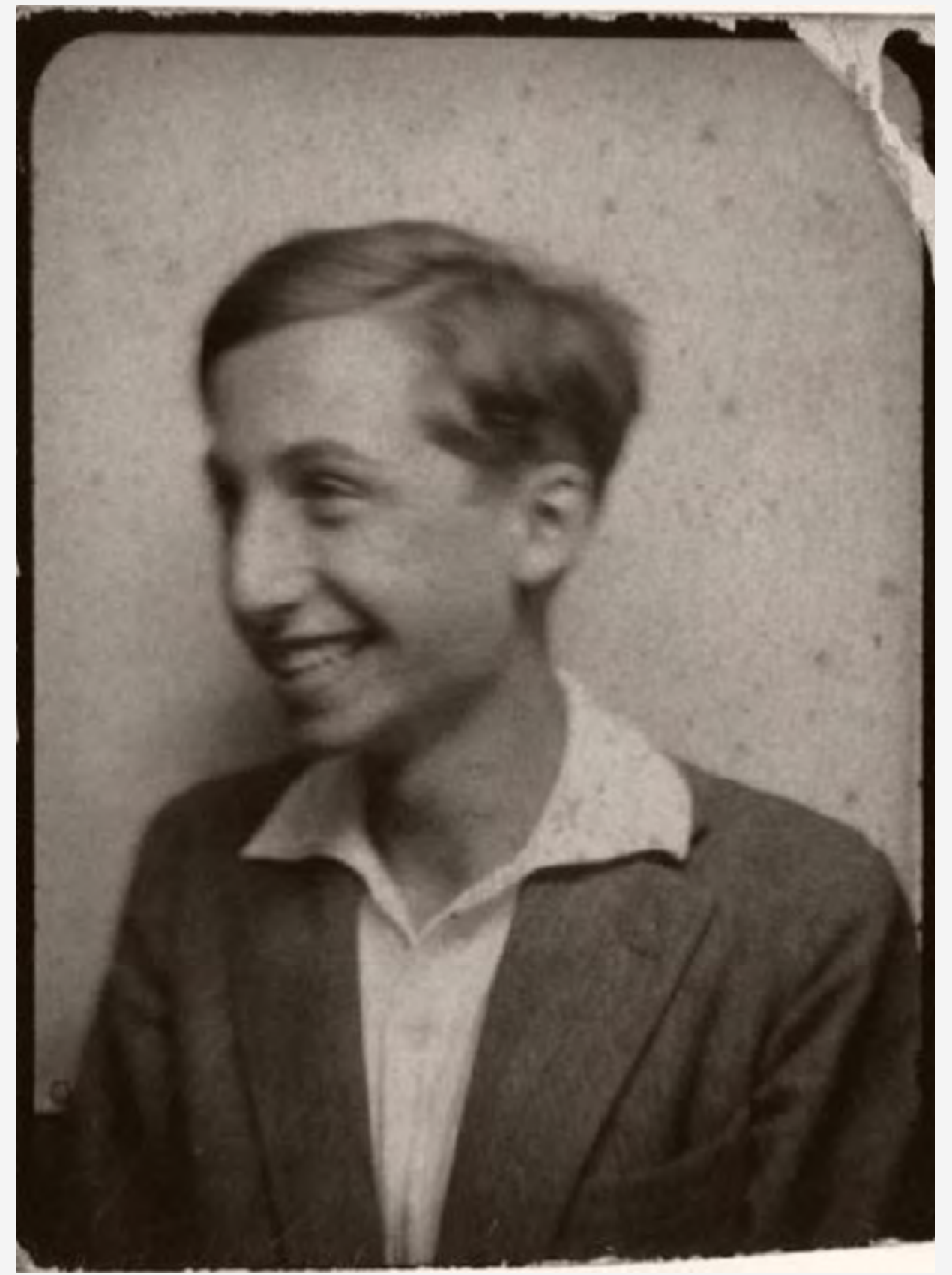

FIGURA 2

Liceu Montaigne

Roland Barthes aos 15 anos, em

930, quando era estudante do

Liceu Montaigne, em Paris. É no

peros que Barthes descobre o gosto pelos dicionários e pela etimologia. 


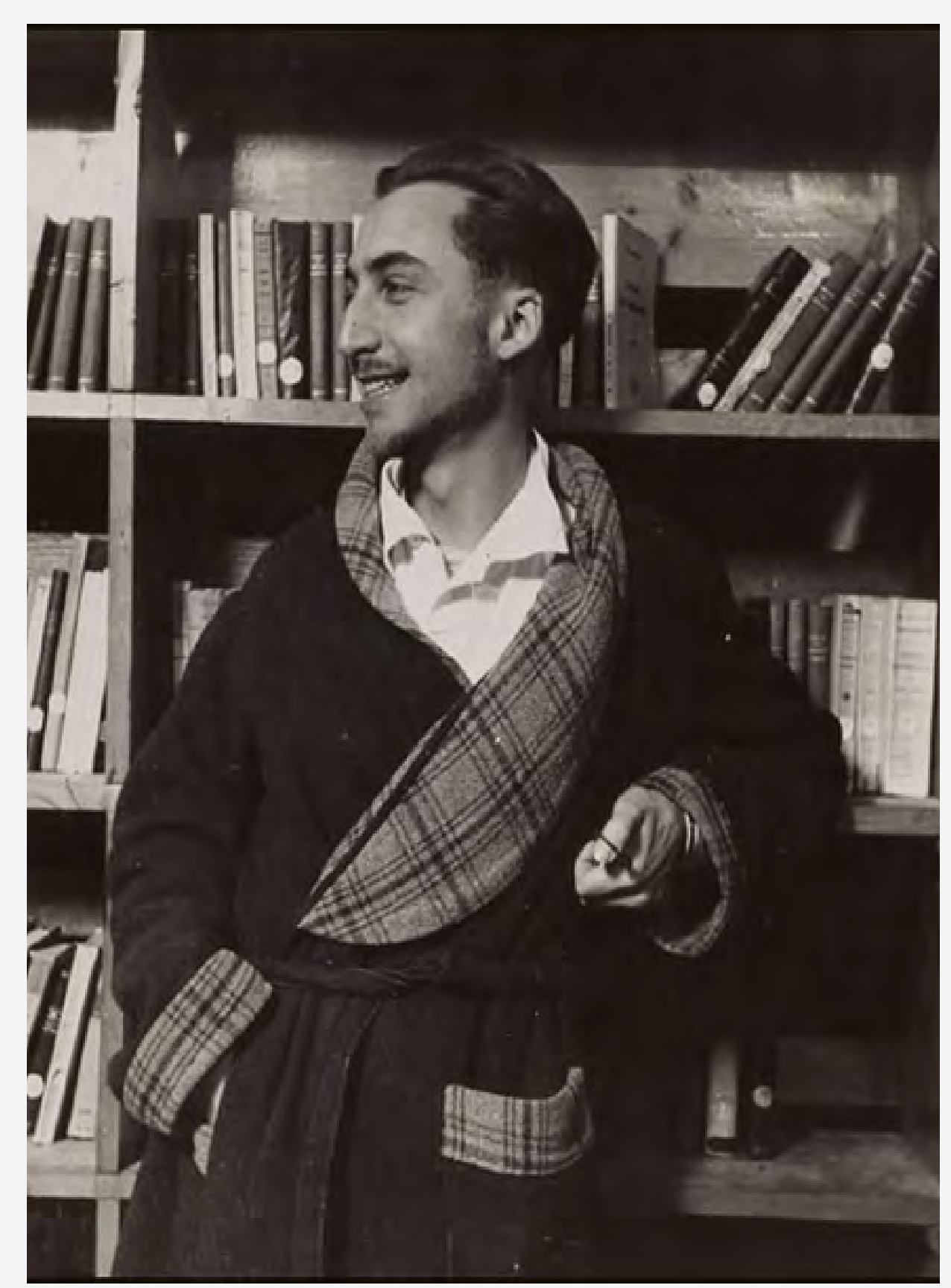

FIGURA 3

Sanatório de Saint-Hilaire-du-Touvet

Roland Barthes aos 27 anos, em

942, quando esteve internado no

sanatorio estudantil de Saint-Hilaire-

du-Touvet para tratamento de

tuberculose. Na revista Existences,

editada pelos alunos e professores

do sanatorio, Barthes publica seus

21

N. 2

MAIO-AG0. 2015

SENRA; SOUZA; CASA NOVA; ORLANDO. 0 lugar de Roland Barthes [...] 


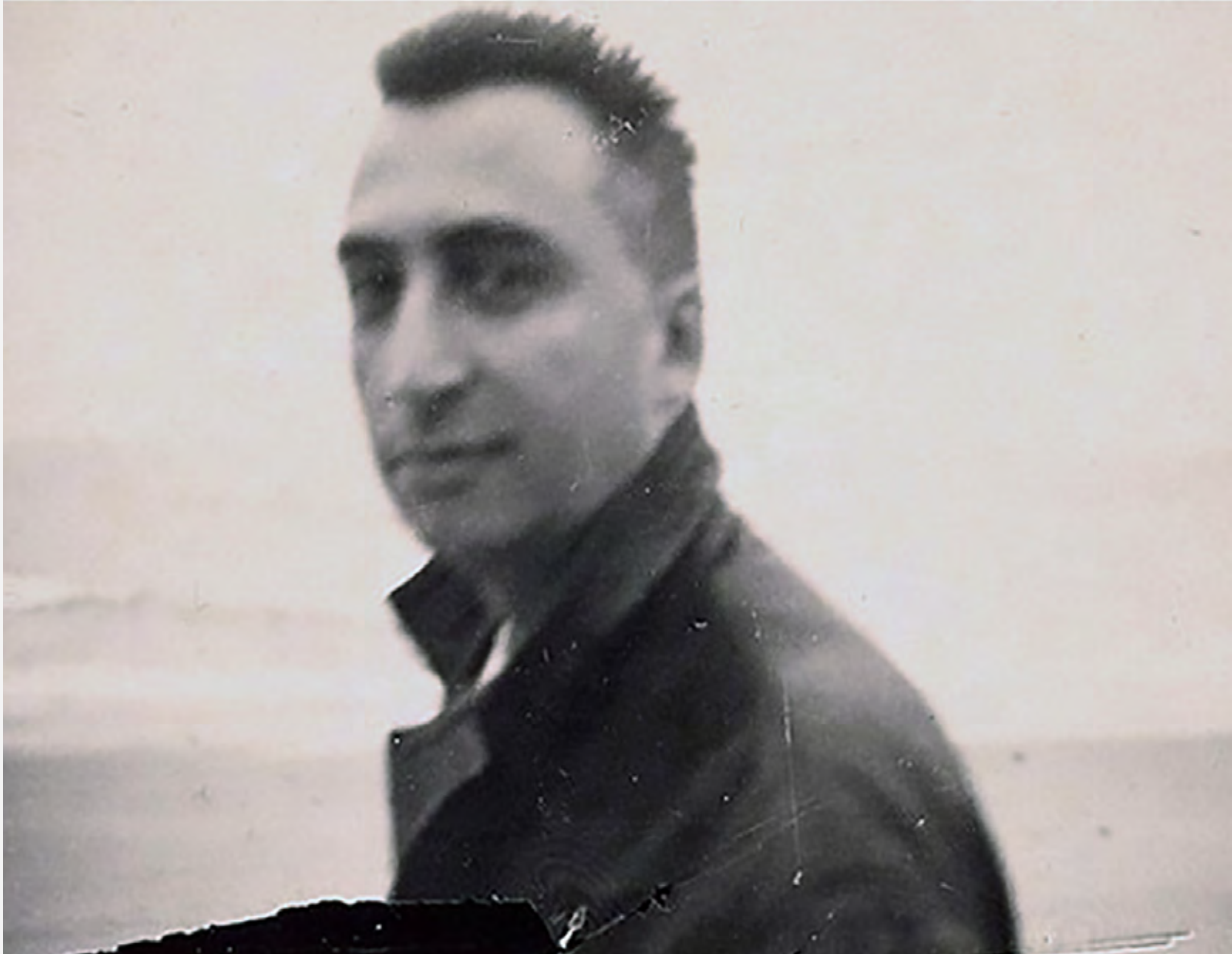

FIGURA 4

Alexandria, Egito

Roland Barthes em 1950, aos 35

anos, durante a temporada em

que trabalhou como professor em

Alexandria, no Egito, onde também

concluiu as pesquisas e rascunhos

do que seria seu primeiro livro

publicado, O grau zero da escritura

(Le degré zéro de l'écriture, 1953). 


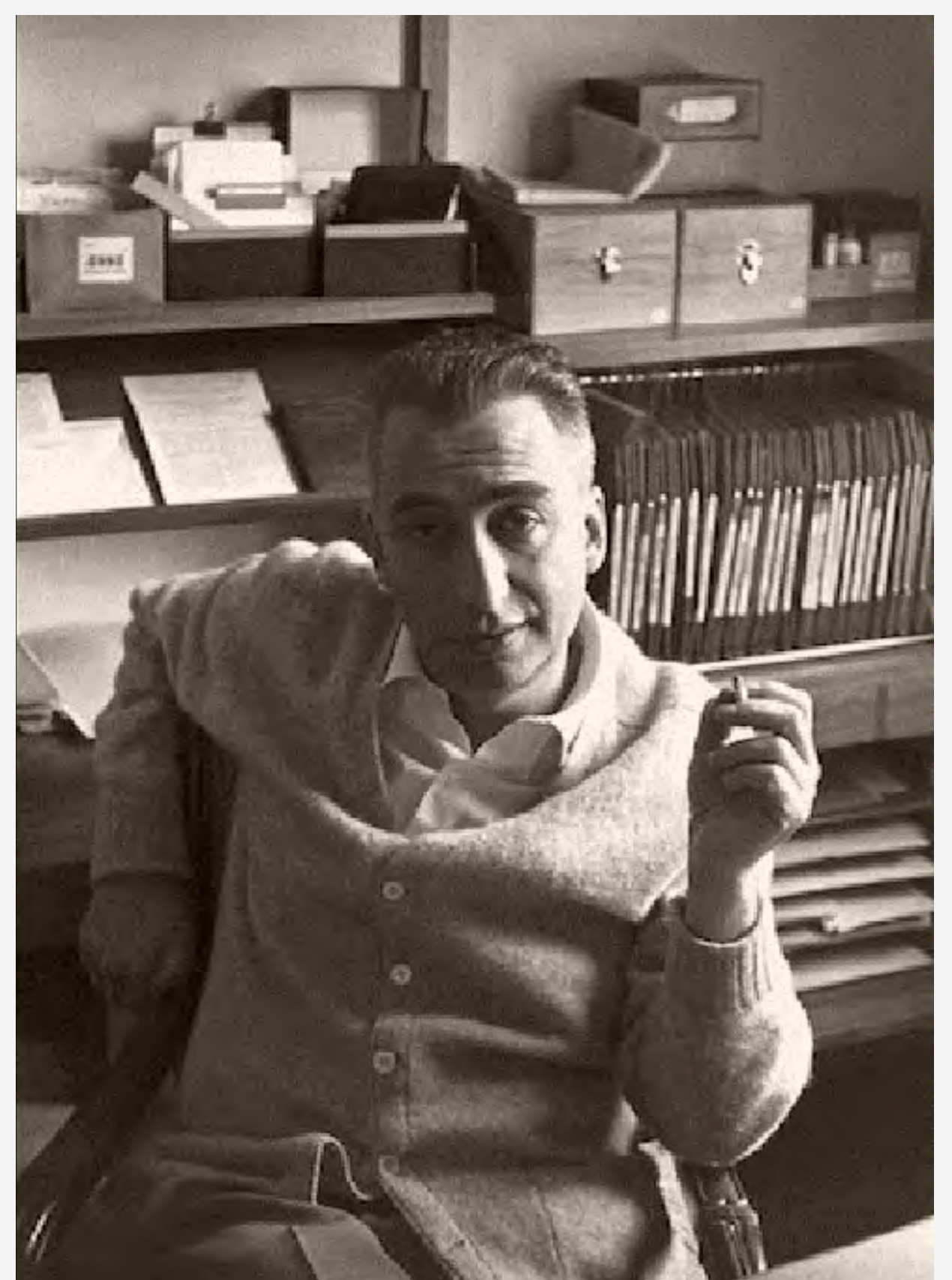

FIGURA 5

Barthes por Cartier-Bresson

Roland Barthes fotografado por

Henri Cartier-Bresson em sua

casa, em Paris, em 1963 - ano em

que publica um de seus livros que

geraram grandes polemicas, Sobre Racine (Sur Racine). 


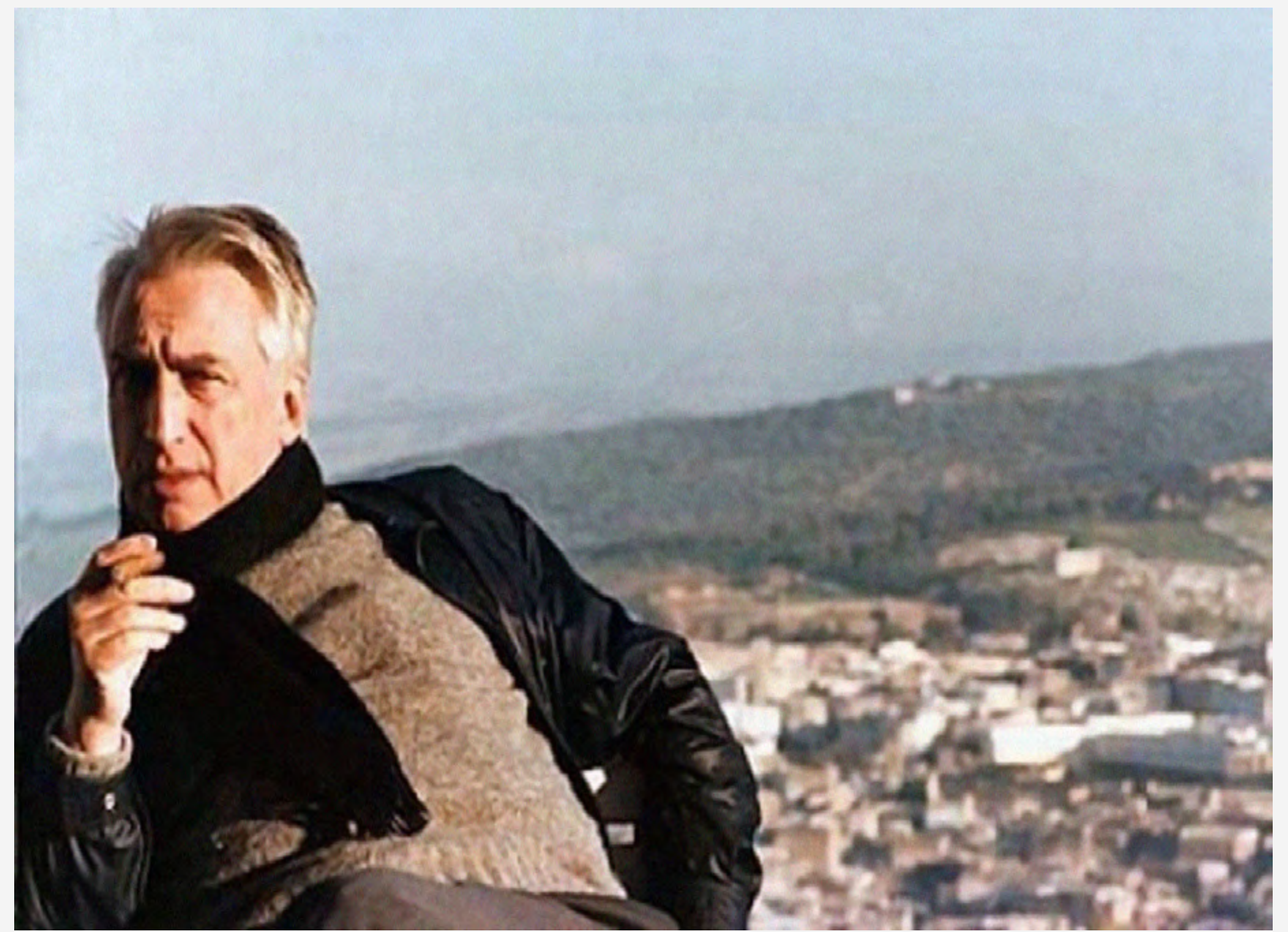

FIGURA 6

Barthes no Marrocos

Roland Barthes fotografado no

Marrocos, em 1969, quando passou

uma temporada naquele país como

professor da Faculdade de Letras

de Rabat. As anotações de Barthes

sobre a temporada no Marrocos

dariam origem ao livro Incidentes

(Incidents, 1987). 


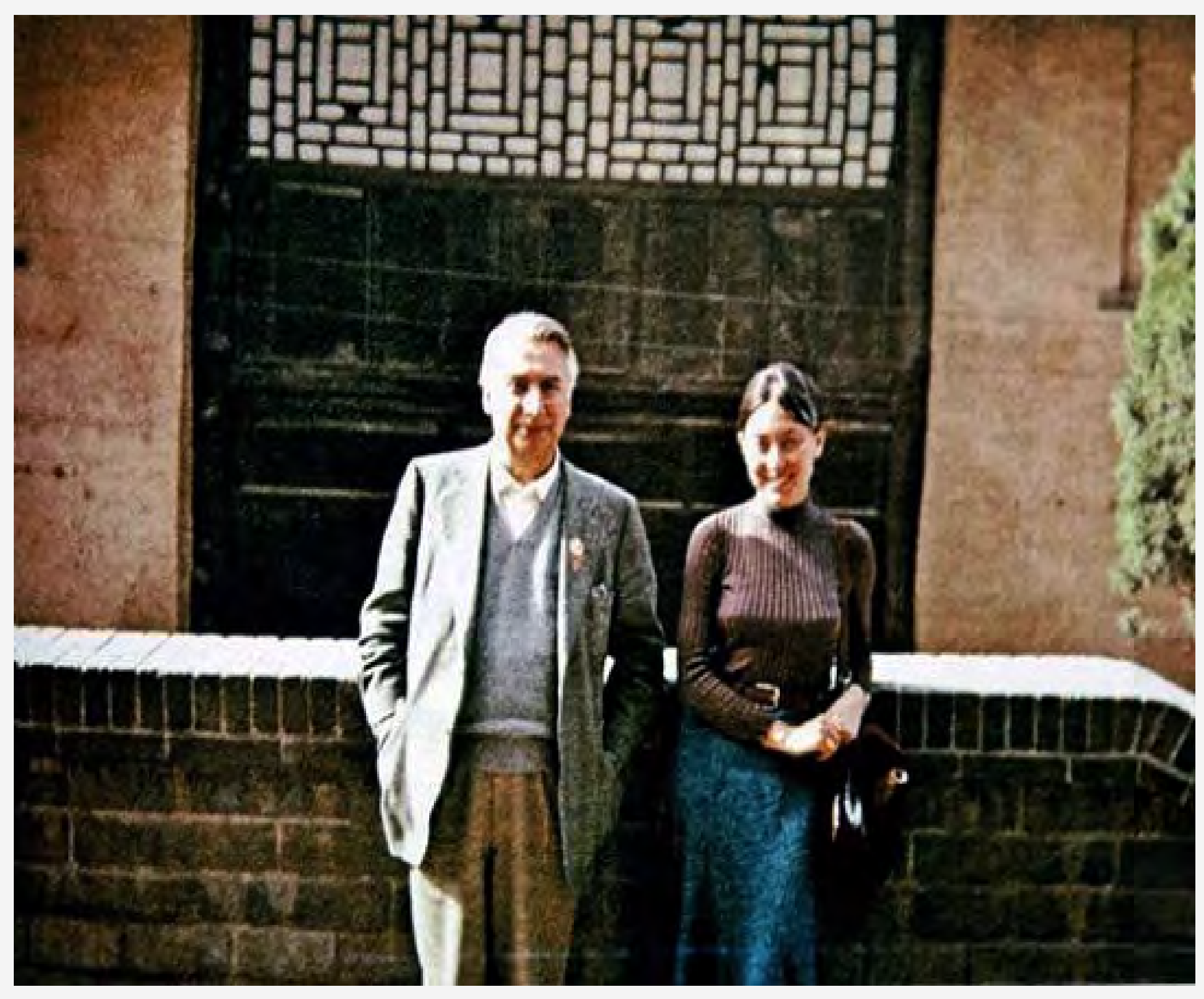

FIGURA 7

Na China com Kristeva

Roland Barthes com Julia

Kristeva durante a viagem de

uma delegação francesa à China

em 1974. Da delegação, além

de Barthes e Kristeva, também

participaram Philippe Sollers,

Marcelin Pleynet e François Wah.

As anotaçoes de Barthes sobre

a viagem foram publicadas no

Wro Cadernos da viagem à China

(Carnets du voyage en Chine, 


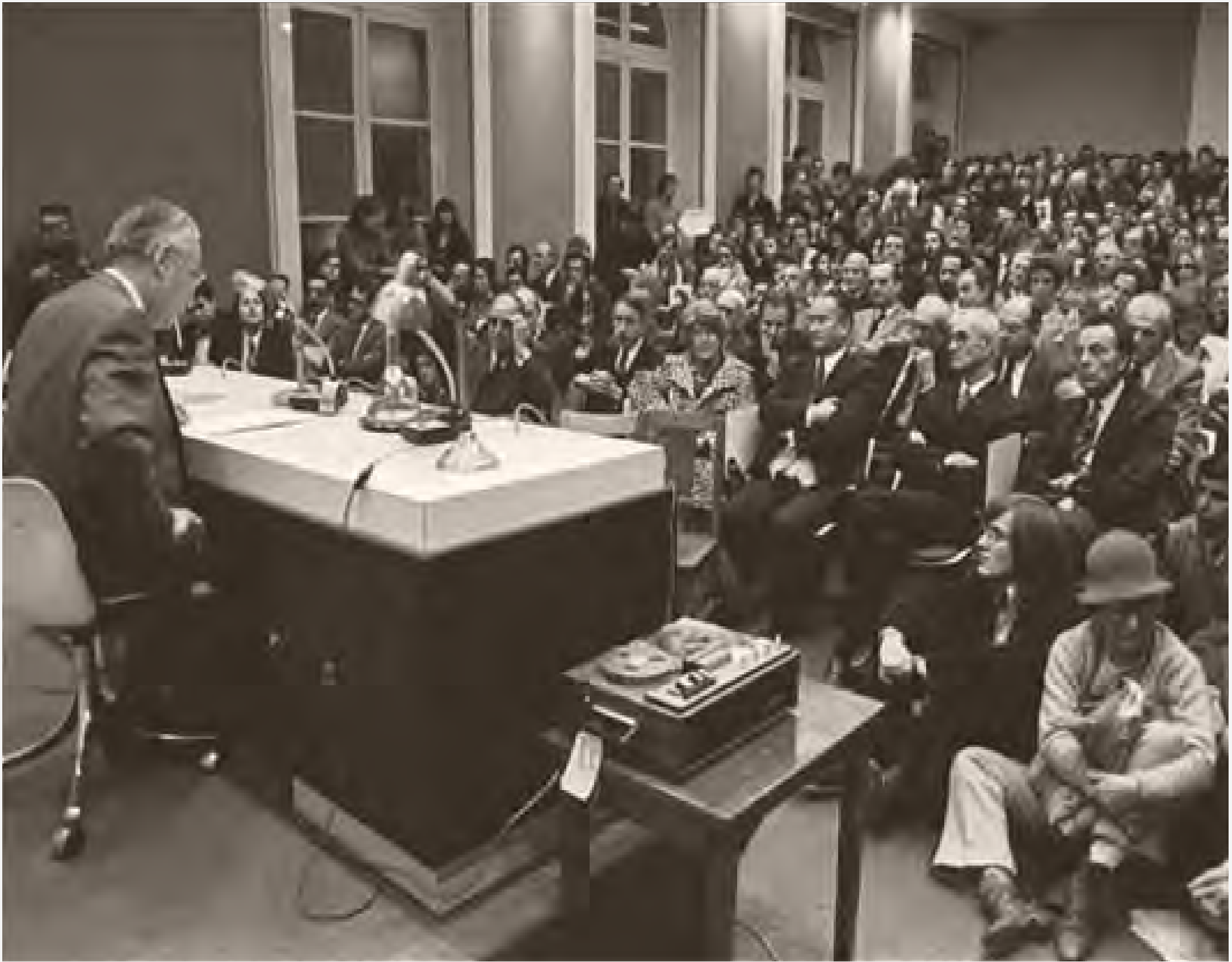

FIGURA 8

Aula no Collège de France

Roland Barthes em 7 de janeiro de 1977, durante sua aula inaugural da cátedra de Semiologia

Literária no College de France, posteriormente publicada no livro Aula (Leçon, 1978). 


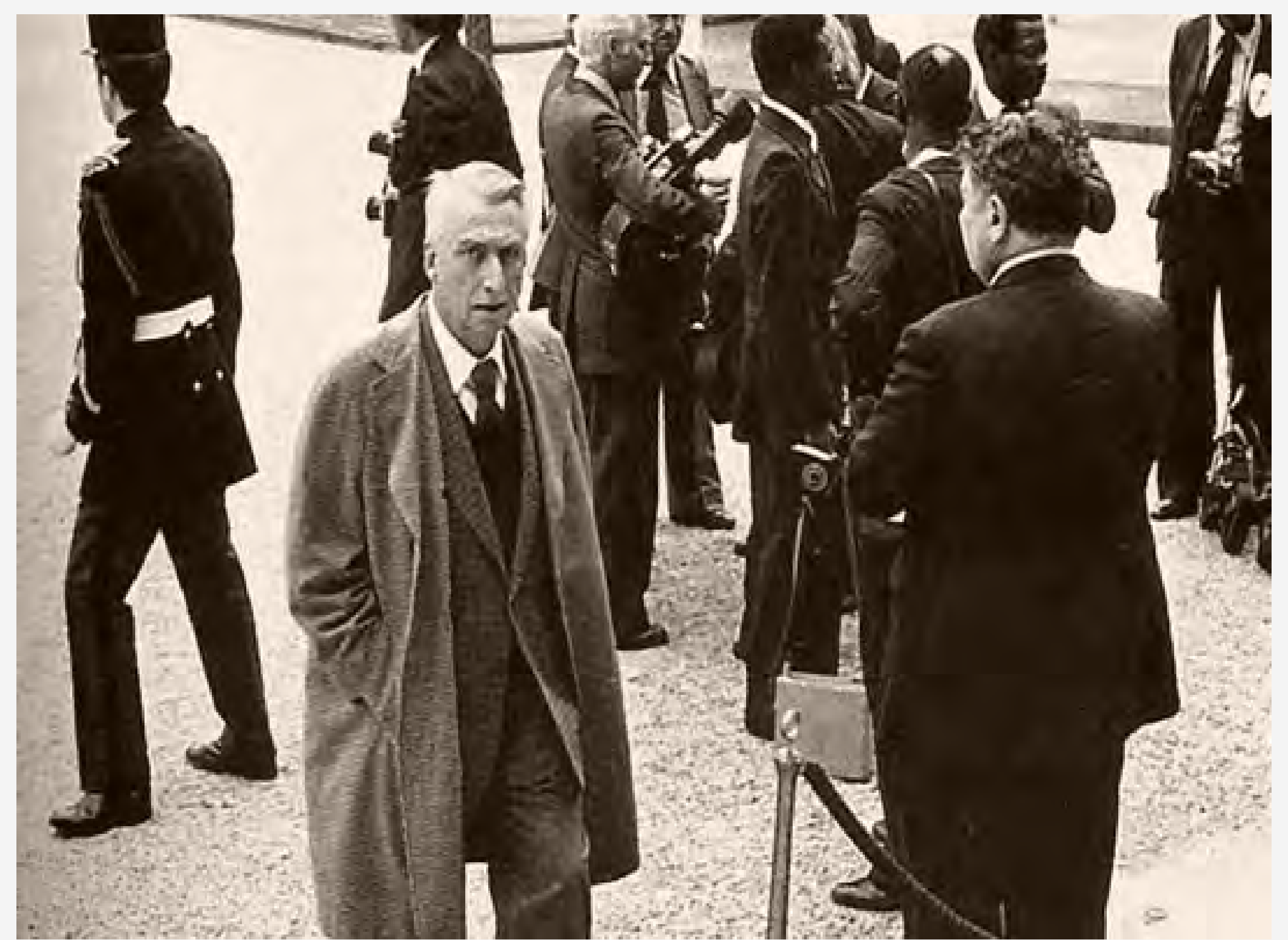

FIGURA 9

A última fotografia

Roland Barthes em sua última fotografia, em 25 de fevereiro de 1980. Barthes enviou os originais para a publicação de A câmara clara e seguiu a caminho do

apartamento de Philippe Serre, na

apartamento de Philippe Serre,

rua Blancs-Manteaux, no Maras,

um almoco jun participaria de

um almoço junto com outros

da França, Francois Miterrand. da França, François Miterrand.

Depois do almoço, quando

retornava para sua casa, Barthes

foi atropelado ao atravessar a

rua des Écoles. Foi hospitalizado,

mas morreria de complicaçós

exatamente um mês depois, em 26

de março. Estava com 64 anos. 


\section{O LUGAR DE ROLAND BARTHES: ENTREVISTA COM} ÂNGELA SENRA, ENEIDA MARIA DE SOUZA E VERA

\section{CASA NOVA}

Mais de três décadas depois de sua morte, as homenagens ao centenário de nascimento de Roland Barthes confirmam sua importância inquestionável como um dos principais pensadores de nossa época e um dos nomes mais influentes de sua geração. Barthes - o professor com "p" maiúsculo que postulou uma "ciência dos signos" - sempre erudito, sedutor, instigante e inquietante, surge nas mais de seis mi páginas de sua "Obra Completa" como um autor de difícil classificação e um "sujeito impuro", na sua própria autodefinição. $\mathrm{Na}$ falta de um rótulo melhor, ele ainda é, quase sempre, chamado de "crítico" - mas talvez mereça ser nomeado, de forma mais gloriosa, como um grande "escritor": um escritor disfarçado de pensador.

O escritor Roland Barthes não busca a diferença entre verdade e aparência. Muito pelo contrário. Para ele, tudo no mundo é aparência, tudo é linguagem e superfície: tudo é texto, inclusive o não-verbal, o pictórico, os afetos, passíveis de interpretações plurais e complementares - como ele próprio argumentou, desde a década de 1950, em suas abordagens de intérprete original da cultura de massas, das instituições literárias, das ideologias e dos mais diversos sistemas de signos codificados na vida cotidiana.
"Se é verdade que, por longo tempo, quis inscrever meu trabalho no campo da ciência literária, lexicológica ou sociológica" - diz Barthes em sua magistral aula inaugural em 1977, no Collège de France - "devo reconhecer que produzi tão somente ensaios, gênero incerto onde a escritura rivaliza com a análise”. A teoria, sutil e original, que emerge dos ensaios de Barthes, com a permanência de sua presença $e$ de sua influência na atualidade, é destacada nesta entrevista com três das professoras que têm importância fundamental como precursoras dos estudos sobre ele na UFMG: Ângela Senra, Eneida Maria de Souza e Vera Casa Nova.

José Antônio Orlando: Escritor, professor, pensador, ensaísta, crítico da literatura, da linguagem, da moda, da mídia, da arte, teórico da semiótica, da semiologia, da cultura? Existencialista, marxista, estruturalista, moderno, pós-moderno? Como podemos definir, hoje, o papel e o lugar de Roland Barthes?

Ângela Senra: Fui aluna de Barthes na Escola Prática dos Altos Estudos, em Paris. Assisti aos seminários "Dez anos de Semiologia. Estudos sobre a política e a sociedade, de Bertold Brecht” (1971/1972). Descobrimos, com Barthes, um Brecht no processo permanente de invenção: ele reinventa citações, chega ao inter-texto. Aos deslocamentos. Uma tarde, antes de 
começar a leitura feita por Brecht de um discurso nazista de Hess, Barthes nos conta, por exemplo, que, no campo marxista, o discurso de Brecht, nunca é um discurso de pregador Roland Barthes é o intelectual, o professor - "desconfiado". Aquele que questiona os mecanismos do poder, subverte as diferentes linguagens. Barthes é o intelectual subversivo, o professor formador de outros intelectuais (situando os imaginários da relação didática). É o homem sóbrio, elegante. Cortês. Polidez nas palavras, nos gestos. Voz baixa. Tranquilidade na fala. Continuei, continuo lendo Barthes. Minha leitura é a leitura do gozo, das imaginações e das fricções - Barthes ensaísta. Fragmentos de um discurso amoroso - ideograma de faltas e de falhas. Barthes romancista?

Eneida Maria de Souza: É por demais notória a importância de Roland Barthes para a crítica literária e cultural. Sua atuação em vários campos do saber, indo da crítica literária às artes plásticas, não cessa de ser reatualizada pelos novos estudiosos nas academias e em pesquisas desvinculadas do saberes institucionalizados. Com a publicação de textos inéditos, como diários e aulas ministradas no Collège de France, tem-se a leitura renovada de seu legado. É preciso separar as diversas fases do intelectual e saber como lidar com as transformações elaboradas por ele na crítica.

Vera Casa Nova: Plural por excelência. Esse o papel de Roland Barthes, ontem, hoje e sempre, sem modismos teóricos. Não há definições para Barthes. Com certeza ele não gostaria de ser de alguma forma rotulado, pois com todas essa funções que você enumerou, ele só poderia ser esse sujeito plural a que me referi anteriormente. Cito ele mesmo: "Eu sou eu mesmo meu próprio símbolo. Eu sou a história que me acontece: uma roda livre na linguagem... Je n'ai rien à quoi me comparer... inumeráveis são as narrativas do mundo...” Sua função foi e será para quem aprendeu a semiologia barthesiana, a desconstrução dos saberes e seus textos.

QUANDO E QUAIS FORAM SUAS EXPERIÊNCIAS COM A DESCOBER TA DAS IDEIAS PLURAIS E DAS GALÁXIAS DE SIGNIFICANTES QUE A OBRA DE BARTHES REPRESENTA?

Ângela Senra: Voltando aos seminários de 1971-1972, Barthes fala que a obra de Brecht elabora uma prática do abalo - uma arte crítica que fissura a crosta das linguagens; uma arte épica que descontinua os tecidos das palavras, distancia a representação sem anulá-la. Barthes propõe, então, que, em se tratando de Brecht, diga-se Sismologia e não Semiologia. Eu me pergunto qual é o lugar desse "sismólogo" no meu mundo. O estudo da literatura francesa desde criança foi fundamental para minha leitura da obra de Barthes. Sua postura crítica, seu olhar sobre diferentes textos, as linguagens diversas, os diferentes traços e sinais foram decisivos para minha formação. $O$ texto do saber me interessa 
sempre. Nunca sem sabor. Assumi, com algum preço, meu texto de afeto (também).

Eneida Maria de Souza: Desde os anos 1960 a obra estruturalista do crítico foi lida e analisada na Faculdade de Letras da UFMG, seja por intermédio de Maria Luiza Ramos, professora de Teoria da Literatura e grande incentivadora de leituras estrangeiras, seja por iniciativa própria, quando Marília Cardoso e eu iniciamos a pesquisa da análise estruturalista, com a ajuda dos ensaios sobre a narrativa de Barthes e de outros, como Todorov e Kristeva. A leitura se realizava sempre em língua francesa, pois as traduções vieram gradativamente e contávamos com o conhecimento da língua para entendermos melhor os textos. Hoje a prática da tradução entre nós facilitou muito. Com a Análise estrutural da narrativa conseguimos penetrar no mundo complicado e muitas vezes fascinante de novas abordagens e da complexidade das teorias sobre o estruturalismo. As portas foram abertas e com isso o interesse por novas descobertas persiste até hoje.

Vera Casa Nova: Minhas experiências se iniciam com um curso ministrado pela professora Dirce Cortes Riedel, em 1968, no Rio de Janeiro, na antiga UEG (hoje UERJ). A partir daí meu olhar sobre o objeto artístico, desde a literatura até a música, a cultura, as mídias, enfim tudo onde Barthes se introduziu, me fizeram e ainda fazem me inquietar. Ele me ensina, a cada vez que o leio, a ser um sujeito incerto.
AS PRIMEIRAS EDIÇOEES DOS LIVROS DE BARTHES NO BRASIL DATAM DE 1970 - COM A PUBLICAÇÃO DE CRÍTICA E VERDADE PELA PERSPECTIVA, DE FATO UMA COLETÂNEA DE ENSAIOS OUE BARTHES REUNIU EM DOIS LIVROS, ESSAIS CRITIQUES (1964) E CRITIOUE ET VERITÉ (1966) - E DE 1971, COM ELEMENTOS DE SEMIOLOGIA, PUBLICADO PELA CULTRIX, QUASE DUAS DÉCADAS DEPOIS DO PRIMEIRO LIVRO DE BARTHES, LE DEGRÉ ZÉRO DE L'ECRITURE, PUBLICADO NA FRANÇA EM 1953. A RECEPÇ̃̃O DE BARTHES FOI TARDIA NO BRASIL?

Ângela Senra: Sim, foi tardia. Na minha opinião, na década de 1960 e mesmo nos primeiros anos de 1970, Barthes ainda "não cabia" no Brasil. O ambiente intelectual era bastante conservador. O golpe militar de 1964 intensificou a linha pétrea de pensamento. Havia alguns intelectuais "à esquerda" mas, eles também, eram dogmáticos. Barthes foi chegando devagar, com outros pensadores que participaram da efervescência cultural francesa de 1968, 1970... Foucault, Deleuze, Guattari, Lacan, Derrida, Blanchot: esses intelectuais deram importante contribuição para a cultura brasileira moderna.

Eneida Maria de Souza: Foi tardia em termos de tradução, mas muitos de nós já líamos seus textos, comprados na Livraria Leonardo da Vinci, no Rio de Janeiro, principalmente quando para lá fui cursar o Mestrado na PUC. Na realidade, este curso me fez ler menos Barthes, pelo interesse em Lévi-Strauss e na antropologia, mas a retomada de sua obra foi feita quando vou para Paris para o Doutorado, em 1978. A partir daí o contato com sua obra foi mais intenso, com as publicações de $A$ câmara
EM TESE
BELO HORIZONTE
v. 21
N. 2
MAIO-AGO. 2015

SENRA; SOUZA; CASA NOVA; ORLANDO. 0 lugar de Roland Barthes [...]

$231-247$ 
clara, de artigos escritos no Nouvel observateur e na sua atenção mais centrada nas disciplinas afins da literatura, como o cinema e a fotografia. Assisti a várias aulas no Collège de France ministradas por ele, as quais me fizeram conviver com sua maneira magistral de proferir conferências. No segundo tempo do curso havia sempre um convidado a falar, entre eles Gilles Deleuze, Octave Manonni, entre outros. Era um espetáculo, assistido pelos estudantes franceses e estrangeiros, entre eles quem passava por Paris por tempo curto.

Vera Casa Nova: Não, nem tanto. Certos professores na universidade, no mundo acadêmico, liam as novidades vindas da Europa, sobretudo da França, na época, fervilhante de ideias. A recepção no Rio de Janeiro, ao menos, não foi tardia. O problema mesmo era a ditadura militar, que aqui, como em Portugal, não aplaudiam as ideias de Barthes. Até hoje não é qualquer um que concebe as ideias de Barthes. A recepção, então, é difícil. Por isso a importância da obra de Leyla PerroneMoisés, que muito nos esclareceu e esclarece até hoje sobre a obra de seu amigo e professor Roland Barthes.

PODEMOS DIZER QUE A DIVULGAÇÃO DA OBRA DE BARTHES NO BRASIL E EM OUTROS PAÍSES TEM SIDO PRODUTIVA PARA O CAMPO DA CRITICA, DA PESOUISA ACADÊMICA E DA CRIACCÃO ARTISTICA?

Ângela Senra: Posso falar com relação ao Brasil, no campo da crítica e da pesquisa acadêmicas (mesmo assim, de forma bastante restrita). Entre 2000 e 2008, participando de bancas de mestrado e doutorado, encontrei excelentes trabalhos com influência barthesiana. Textos acadêmicos de saber e de sabor, ensaios de crítica criativa que acrescentaram reflexões sérias e informações importantes para meus estudos.

Eneida Maria de Souza: Hoje seu legado é mais do que comprovado. Os estudos de memorialismo, autobiografia, autoficção e, principalmente, de ensaio receberam um impulso muito grande com a reviravolta realizada a partir da década de 1970, com o livro O prazer do texto, um convite à leitura prazerosa e ausente de prisões conceituais, permitindo à crítica se desvincular do seu aspecto fechado e acadêmico. Não resta dúvida, porém, que um de seus textos mais discutidos e polêmicos, publicado em 1968, "A morte do autor", tenha sido motivo de muitos equívocos interpretativos. Por essa razão, até hoje é necessário ponderar sobre os efeitos benéficos do ensaio, ao lado dos maléficos. "A morte do autor" seria melhor interpretado como sendo a reação à crítica de ordem biográfica que até então se fazia, da pior qualidade. $\mathrm{O}$ afastamento do sujeito autor da obra indicava a sua transformação em personagem, o que Barthes irá realizar quando escreve sua autoficção: Roland Barthes por Roland Barthes. Embora não aceite mais a prerrogativa de matar o autor, este ressurge também sob a forma de ficção, não de carne e osso. O conceito de biografema atua ainda mais na perspectiva de não ser possível 
se atingir a totalidade e sim a prática do fragmento, seja de biografias, de cenas ou de desejos.

Vera Casa Nova: Acredito que sim. Aqui no Brasil, na maior parte da América Latina e nos Estados Unidos. Sobretudo a partir de alguns professores e pensadores, vejo as palavras da crítica e dos objetos artísticos como vestígios importantes do pensamento barthesiano.

QUAIS SERIAM AS PRINCIPAIS CONTRIBUIÇÕES DE BARTHES DIANTE DA VANGUARDA CRÍTICA DE NOSSO TEMPO?

Ângela Senra: Barthes, mutante, marca a vanguarda do nosso tempo. Mantem, em cada passo da sua trajetória, uma postura coerente nos seus deslocamentos, no seu processus. A cada nova posição crítica acrescenta a(s) anterior(es) Barthes é um homem do seu tempo. Ético. Cortês. Um homem da pólis. Politicamente à esquerda ("desconfiado").

Eneida Maria de Souza: Na década de 1980, a influência de Barthes pode ser considerada sob duas vertentes: a primeira, em relação à abertura ensaística e à proliferação de estudos sobre outras áreas do saber, como a fotografia, as artes plásticas e a psicanálise, disciplina por ele assumida por influência da teoria lacaniana. $\mathrm{O}$ avanço neste sentido foi de muito ganho para a crítica; a segunda, diz respeito ao excesso de experimentações de seus adeptos, culminado no culto de uma linguagem por demais fragmentada e na écriture. A exposição exacerbada e piegas do sujeito muitas vezes resultava na crença de ser a crítica a manifestação natural de sentimentos até então reprimidos. Ainda bem que esta onda passou. Os resquícios desta écriture são hoje muito bem elaborados.

Vera Casa Nova: Do meu ponto de vista, seriam contribuições a partir dessa pluralidade, da inter e da transdisciplinaridade (o nome é péssimo, acho que Barthes não o empregaria). Mas a vanguarda crítica se volta para uma crítica escritural. Para mim, Marcos Siscar, Ângela Senra, Paula Glenadel, Lucia Castelo Branco, Eneida Maria de Souza, entre outros, têm nas veias um pouco de sangue barthesiano. Acredito que não são mais porque a academia ainda guarda um discurso que os impede. Esse desejo de uma outra escritura que a crítica tem apresentado já é a contribuição maior de Barthes.

POR QUE BARTHES PERMANECE TÃO ATUAL E TÃO IMPORTANTE PARA COMPREENDER AS QUESTÕES NÃO SO DA LITERATURA, MAS TAMBÉM DA ARTE CONTEMPORÂNEA E DA COMUNICAÇÃO DE MASSA?

Ângela Senra: O mundo crítico de Barthes - a pluralidade das linguagens, os jogos intertextuais, os espaços ideogramáticos, os rumores das línguas (glossolálias?), os deslocamentos do espaço ("onde começa a escritura? Onde começa a pintura?”) - são molduras para a arte 
contemporânea e para a comunicação de massa. Para o balé, as instalações, a pintura, a fotografia... Quanto à comunicação de massa, uma questão bastante grave se coloca para mim. Acho muito complexo, impossível mesmo, ler os jornais impressos e a televisão com as lentes bicolores do politicamente correto.

Eneida Maria de Souza: Com as devidas ressalvas, Barthes é hoje um dos intelectuais mais respeitados no mundo. A crítica à sua obra, feita pelos pensadores avessos à textualidade e à abordagem semiológica, deveria observar que ele foi um dos principais analistas da cultura de massa, com o livro Mitologias, da década de 1950. Não se deve, contudo, privilegiar este ou outro autor em detrimento de outros, mas de abraçar cada vez mais outros, o que enriquece nossa compreensão das teorias. A sobrevivência deste ou de outro autor deverá passar pelo crivo dos pontos frágeis e dos fortes, das associações entre o que se pensa hoje e como estas ideias ainda poderão ser recicladas. Matar ou ressuscitar autores não são atitudes do historiador de cultura. A sobrevivência das teorias independe dos conceitos de início ou de fim das ideias. Permanece quem ainda é contemporâneo e, por esta razão, se insere e se afasta do presente. E Barthes se enquadra neste feitio.

Vera Casa Nova: Barthes continua atual e importante. No evento em comemoração ao centenário, "Roland Barthes
Plural”, realizado em junho na Casa das Rosas, em São Paulo, vi isso claramente. Quem lê Barthes ama-o e essa afetividade, como ele queria que fosse nossa maior potência, deixa-nos impregnados e, ao citar suas ideias e textos, os atualizamos. Mais uma vez volto a falar sobre esse olhar marcado pela Semiologia: o olhar que persegue os sentidos (e os não-sentidos), em qualquer arte, e sobretudo o olhar crítico sobre a comunicação de massa.

PARA AQUELES QUE QUEREM CONHECER ROLAND BARTHES, QUAIS LEITURAS SÃO FUNDAMENTAIS? E PARA OS LEITORES OUE JÁ CONHECEM A TRAJETÓRIA DE BARTHES, QUAIS AS SUAS SU GESTÕES DE LEITURA ENTRE OS LANÇAMENTOS RECENTES?

Ângela Senra: Para quem quer conhecer Barthes: O grão da voz; Entrevistas: 1962-1980; Crítica e verdade; O grau zero da escritura; O prazer do texto; Roland Barthes por Roland Barthes; Aula; Fragmentos de um discurso amoroso; Mitologias; O império dos signos; Incidentes; Roland Barthes por Leyla Perrone-Moisés. Para quem já conhece Barthes: A câmara clara e Diário de luto; Inéditos, volume I, teoria; Como viver junto; Sollers escritor; Viver com Barthes (organizado por Vera Casa Nova e Paula Glenadel); Blanchot: l'amitié; Alain Robbe-Grillet: por que amo Barthes; Natalie Ginzburg: as pequenas virtudes; Beatriz Sarlo: viajens (virtual); Sebastião Salgado: gênesis; e Claudia Andujar: marcados (fotografias de índios Yanomami acompanhadas de ensaio de Stella Senra). 
Eneida Maria de Souza: Os livros da década de 1970, todos, e os recentes, que são póstumos. Roland Barthes por Roland Barthes é leitura de cabeceira. Considero Diário do luto um livro imprescindível para quem trabalha com autobiografia; Aula, de importância crucial para quem é professor e crítico Como viver junto e A preparação do romance (I e II), para quem não desiste de conviver com o inacabado e o fragmentário, por se tratar de publicação sobre os últimos cursos ministrados no Collège de France.

Vera Casa Nova: Uma fonte importante de pesquisa é o site http://roland-barthes.org que mostra a atualidade de Barthes. Quem lê Barthes vai atualizando seus textos. Além do mais, quem lê Barthes ama Barthes ou odeia Barthes. Gosto dessa não unanimidade, que coloca em jogo a afetividade, como ele queria que fosse. Ao citar seus textos residualmente já estamos atualizando-o. Para quem ainda não conhece Barthes, minhas sugestões são as leituras de Mitologias, Fragmentos de um discurso amoroso e A câmara clara. Para os que já conhecem Barthes, vale a releitura e uma consulta ao site. 